International Journal of Child, Youth and Family Studies (2015) 6(4): 498-515

\title{
AN ETHOS FOR THE TIMES: DIFFERENCE, IMAGINATION, AND THE UNKNOWN FUTURE IN CHILD AND YOUTH CARE
}

\section{Jennifer White}

Acknowledgment: A version of this paper was originally presented as a Keynote Address at the CYC in Action Conference IV: Responding to our Times, University of Victoria, Victoria, British Columbia, Canada, May 2, 2014.

Jennifer White, Ed.D., former co-editor of the International Journal of Child, Youth and Family Studies, is Director and an Associate Professor in the School of Child and Youth Care, University of Victoria, P.O. Box 1700, STN CSC, Victoria B.C., Canada, V8W 2Y2. E-mail: jhwhite@uvic.ca 
International Journal of Child, Youth and Family Studies (2015) 6(4): 498-515

What does it mean to develop an "ethos for the times" when the times we are living in are marked by ongoing change, unpredictability, and uncertainty? How do we make sense of, and actively engage with, the complexities that surround us? What ideas, values, and frameworks can help us, and those we work with, to feel most alive to our mutual potentials and collective possibilities? These questions provide a point of departure for thinking about Child and Youth Care (CYC) in the 21st century. In a world that is always on the move, we need to constantly re-evaluate our theoretical and practice frameworks to determine if they are useful and relevant for the times in which we are now living. As Ulrich Beck (2000) put it, “[the] attempt to apply nineteenth-century ideas to the twenty-first century is the pervasive category mistake of social theory, social sciences and politics" (emphasis in original, p. 224). Recognizing that the field of CYC is itself a site of contested meanings, where ongoing debates about identities, roles, boundaries of practice, and professional status continue to animate the field, the aim of this piece is not to argue for more certainty, specificity, or role clarity. On the contrary, it is a call for increased plurality, greater imagination, and an ongoing openness to the unknown future.

\section{Starting Places}

In the spirit of starting off in a good way, it is important to acknowledge the significance of place, history, and politics in the work that we do as CYC practitioners, educators, and scholars. For example, the University of Victoria (where I am writing from) is located on unceded Coast Salish and Strait Salish Territory. Whenever we gather in public for conferences or other formal events, it is common to hear speakers acknowledge the territory we are on. Lately I have been wondering whether some of us need to move beyond a mere reciting of this fact (which seems a bit too easy), towards a more explicit naming of whiteness, racism, and the violent practices of cultural invasion that marked the arrival of many of our European ancestors to these territories. When we move away from simply acknowledging the Indigenous territory we are on, we are potentially stepping towards a "responsibility-based ethic of truth-telling" which is ultimately "a call for justice and the return of stolen lands/waterways to the Indigenous peoples who maintain special relationships to these places” (Snelgrove, Dhalmoon, \& Corntassel, 2014, p. 4). This position is also consistent with what Jennifer Harvey (2007) calls "racial justice making”. She writes:

To locate our role in fighting white supremacy and to struggle for justice with integrity and effectiveness requires that those of us who are white interrogate for the purposes of response and action - who we are as racial subjects. (p. 8)

For Canadians, we are living in a nation that came into being through the theft of Indigenous people's land and a disavowal of Indigenous sovereignty. Ahmed (2004) suggests that when we "unlearn the forgetting of this history" (p. 36), we can no longer remain the same. By calling attention to the historical, political, and institutional relations that structure our personal and professional lives in ways that serve to reproduce white privilege and by recognizing how we are all implicated in the ongoing legacy of colonization, we begin to take steps towards more just racial relations. 
International Journal of Child, Youth and Family Studies (2015) 6(4): 498-515

The move to explicitly name whiteness and racism, while a step in the right direction, is somewhat problematic, though, as it may have the undesired effect of positioning the author (in this case, me) as "the right kind of white person" or "the good white person”. As Chapman, Hoque, and Utting (2013) put it, “white people's naming of racism [frequently] contributes to their exaltation as moral and as on the side of justice" (p. 35). I will say a bit more about how complicated all this is (see also Hoskins, 2012; Skott-Myhre \& Little, 2014), but for now, I will just note that Child and Youth Care, as a professional field of helping, is never innocent or outside of this colonial history (Little \& Walker, 2014; Loiselle, de Finney, Khanna, \& Corcoran, 2012; Saraceno, 2012; SkottMyhre, 2006).

\section{Key Concepts}

Two key ideas have been particularly influential in shaping the overall tenor of this paper. The first is from Steve Fuller (2014) who recently blogged about the role of public speaking in academia:

Keynote speeches should be about challenging the taken-for-granted assumptions of the field, but in a way that enable the audience to go forward. In other words, however critical one is of the field, there must be a sense that field contains the resources to move forward. (para. 6)

The second influential idea is taken from a quote that sits above my desk:

To look with planned emptiness is deliberately to cultivate an area in one's mind that is reserved for the unknown, that is ready to accommodate the new, perhaps alien idea, and experience it, rather than rationalize it away or avoid it (Middleman \& Wood, 1990, p. 24).

With this as my backdrop, my aim is to offer an appreciative critique of the field of CYC; leave room for the not yet known; and through the use of questions and provocations, open up new possibilities for fresh thinking. To help me move in these directions, I have been inspired by Sara Ahmed's work on diversity, ethics, and the cultural politics of emotion (Ahmed, 2004; 2012). I have also been reading Henry Giroux's (2014) ideas around critical pedagogy and the threat that neo-liberalism poses to higher education. Ronald Barnett's (2000; 2012) ideas on supercomplexity have been particularly useful in helping me reconceptualize some of the challenges we face as CYC practitioners, educators, and scholars.

Through my Twitter feed I have discovered Hybrid Pedagogy, a digital journal that seeks to disrupt the distinctions among students, teachers, and learners. This journal offers a series of thoughtful articles for rethinking teaching and learning for the 21st century, with implications for CYC education. The creative work of Julian Stodd, who writes (and illustrates) a blog on the topic of the social age, social leadership, and collaborative learning, has also been an important touchstone. I am also building on the important work of many CYC scholars who have been thinking and writing about 
International Journal of Child, Youth and Family Studies (2015) 6(4): 498-515

diversity, ethics and, sociopolitically informed approaches to practice in theoretically robust and imaginative ways (deFinney, Little, Skott-Myhre, \& Gharabaghi, 2012; Hoskins, 2012; Pacini-Ketchabaw, 2014; Skott-Myhre \& Little, 2014; Kouri, 2014; Loiselle et al., 2012; Newbury, 2009).

\section{We Are All Implicated}

As most of us know by now, we are born into a world with a playing field that is anything but level. It is a myth to say that every person has the same opportunity to flourish, succeed, or prosper as long as she works hard enough. This is because there are many systemic and structural barriers that create disadvantages for some groups but not others. To say we are all implicated does not mean we are all equally implicated. Transnational feminist frameworks have helped to show us that we are all multiply constituted as well as differentially privileged and disadvantaged along complex intersecting lines of race, class, ability, gender, sexual orientation, and age - all of which play out within particular institutional hierarchies and specific localities (Deepak, 2012; Lee \& deFinney, 2008; Patil, 2013; Saraceno, 2012). Because existing systems of domination are interlocking, Fellows and Razack (1998) remind us that we must continuously resist the temptation to view forms of oppression as somehow unrelated. More specifically, they warn us against the dangers of thinking about ourselves as innocent. No one is innocent and "(w)hen we view ourselves as innocent, we cannot confront the hierarchies that operate among us” (p. 335).

The field of CYC, like most fields of professional helping, has emerged out of a Euro-western, liberal humanist tradition and has been strongly influenced by colonial logic and the ideals of the Enlightenment (de Finney et al., 2012; Saraceno, 2012; SkottMyhre, 2006). Among other things, this includes the acceptance of the bounded, autonomous, and individual Western self as natural and desirable, coupled with an unquestioned faith in the value of professional interventions and expertise (Wexler \& Gone, 2012; White, 2011). Meanwhile normative assumptions about "the good life", "the healthy child", "the productive citizen”, and "the successful, functioning family", combined with dominant conceptualizations of "research”, "knowledge”, and “expertise”, exert a strong but often unspoken influence on our practice and research activities.

For example, within the dominant empiricist tradition, it is assumed that "there is a real world with real attributes, and that it is the job of social science to discover those of social or political significance” (Law \& Urry, 2004, p. 393). By contrast, I am starting from the premise that our received ways of thinking about and engaging with the social world are not neutral or required, but are highly productive. In other words, "[t]hey do not simply describe the world as it is, but also enact it” (p. 391, emphasis added). The corollary of this is that other descriptions, possibilities, framings and other ways of imagining how we might go on together are always available (Gergen, 2009).

If we want to "respond to our times" then, one place to start might be to move towards a more complicated reading of Child and Youth Care. I have in mind here a form of engagement that takes us beyond the familiar formulation of CYC as a set of neutral 
International Journal of Child, Youth and Family Studies (2015) 6(4): 498-515

approaches, professional competencies, ethical codes, or ahistorical relational interventions towards a more nuanced, uncertain, politicized, and dynamic rendering. What is being envisioned here is akin to Jeffery and Nelson's (2011) understanding of the ethical encounter whereby "power relations and social inequalities are understood to infuse the very core of relationship, rather than complicated 'extras' to be transcended in favour of a comfortable exchange” (p. 248). Such an orientation invites us to consider both the sources of social suffering as well as our own complicity in reproducing inequitable social arrangements through our professional practices, research methodologies, and institutional and social locations (Newbury, 2009; Prilleltensky, Rossiter, \& Walsh-Bowers, 1996).

Importantly, this way of working means occupying and negotiating many unexpected and potentially contradictory spaces simultaneously. Braidotti (2010) recognizes the paradoxical nature of this type of affirmative politics, "which entails the production of social horizons of hope, while at the same time doing critical theory, which means resisting the present” (p. 42). Along similar lines, Tuck (2009) argues for more "desire-based frameworks" which are not predicated on documenting or fixing other people's pain, damage, or victimhood and do not require us to pledge allegiance to one (or the other) side of an enclosed logic or irreconcilable binary such as structure/agency or individual/social. As she puts it, "We can desire to be critically conscious and desire the new Jordans [sneakers], even if those desires are conflicting” (p. 420).

Thinking with these theorists, for the purposes here, I am most interested in thinking about "what CYC does" and "what it might become" and the productive possibilities of theorizing the CYC field as a kind of "ethos" - or way of doing things that is rooted in a strong set of ethical, political, and ontological commitments and entanglements:

- As CYC practitioners and scholars, how do we develop ways of going on together that are relevant for the times in which we are all living?

- What kind of social world and ways of being are we aspiring to?

- What new vocabularies, values, practices, and politics might be required to engage with the current complexities?

I will begin by bringing to the surface some of the overlapping social and political forces that are shaping our lives as we attempt to work, study, and live in the 21st century. This is by no means an exhaustive accounting and of course it is inflected with my own intellectual and political commitments, which draw from various strands of critical, constructionist, feminist, post-structural, and post-colonial ideas (Ahmed, 2012; Barnett, 2012; Braidotti, 2010; Gergen, 2009; Tuck, 2009). Next I will offer some tentative ideas and resources for moving forward in these unsettled times. These are not prescriptions or attempts to replace what currently exists or foreclose on what else might be possible. I hope some of these ideas will provide points of connection and offer new openings for creative thought. 
International Journal of Child, Youth and Family Studies (2015) 6(4): 498-515

\section{Contextualizing Our Times}

We are living in a globalized world that is marked by growing interdependence, unprecedented cross-border movements, and a constant flow of people, information, knowledge, technologies, products, and capital. Globalization commonly refers to "the widening, deepening and speeding up of worldwide interconnectedness" (Held, McGrew, Goldblatt, \& Perraton, 1999, p. 14). While calls to educate "global citizens" and the promotion of "global mindedness" permeate educational and professional discourses today, globalization is actually a highly contested term (Roman, 2003) and the effects of globalization are uneven, bringing benefits to some groups, often at the expense of some others. For example, not everyone has a choice about moving from their homelands and many children and families around the world are living as refugees, without the basic rights and protections of citizenship (diTomasso, 2012). We need to ask ourselves how our theory and practice frameworks in CYC help us to think and respond to an increasingly complex and globalized world in ways that do not replicate what Roman (2003) describes as overly simplistic colonial discourses (e.g., the perception of the nonWestern "global” figure as the Other to the local Western self).

We are also living under the pervasive influence of neo-liberalism, an ideology and mode of governance that casts all dimensions of life in terms of a market rationality. We see this, for example, within certain contexts of higher education, where competition and profit-making are central organizing features. Here, students become consumers, faculty become entrepreneurs, and universities become corporations (Giroux, 2014). We can also see clear evidence of the neo-liberal currents shaping the way we think about ourselves and the children, youth, and families we work with through the language we deploy: measuring up; bottom line; quick wins; doing more with less; targets and benchmarks, and auditable practices. In other words, we are constantly being expected to demonstrate our value in the marketplace. How does the language and logic of the market potentially limit or distort the ethical project of caring for those who may be vulnerable, dependent, or socially excluded? When care becomes commodified, what are the implications for children, youth, families, and communities?

Meanwhile, through the highly visible Occupy Movements, most of us are very aware that the gap between rich and poor is growing, which means that we are living in a time of growing inequality. Structural violence is a term that has been used by many to refer to the devastating impact of social inequality, systemic forms of racism, and social deprivation on marginalized populations (Farmer, 2003). Oftentimes children, youth, and families are blamed for their plight even though unjust structural arrangements are known to produce and perpetuate inequalities. Farmer argues that "hiding this suffering, or denying its real origins, serves the interests of the powerful” (p. 17). A contemporary example of this form of concealment from my own practice is the way in which suicides among young people are often framed exclusively in terms of individual mental health problems. Meanwhile, sociopolitical factors, structural forces, and relations of power (e.g., racism, colonization, heteronormativity), all of which make significant 
International Journal of Child, Youth and Family Studies (2015) 6(4): 498-515

contributions to the emergence of distress and hopelessness among young people, are very often obscured from view (White, 2012). This can result in an invidious form of victim blaming whereby we "train the disenfranchised to remediate their personal deficits and adapt to the status quo" (Fondacaro \& Weinberg, 2002, p. 481).

In recent years, a large body of evidence has begun to accumulate which demonstrates the undeniable role that the social determinants of health play in shaping children's health and well-being. The social determinants of children's health (SDCH) include the following: quality child care, housing and food security, income and wealth distribution, and public policy and government intervention (Raphael, 2014). As CYC practitioners who prize holistic and contextually responsive approaches (Newbury, 2009; White, 2007), it is worth asking ourselves how well we take into account the sources of suffering in our work with children, youth, and families, and how well our preferred practices address the broader sociopolitical and historical influences on well-being (Aldarondo, 2007). If we fail to engage with the social and structural conditions that have such a clear and strong influence on the well-being of children, families, and communities, our efforts are bound to be inadequate. Perhaps even more importantly, we place an unfair burden on CYC practitioners when we suggest that they could somehow overcome the political and structural forces that contribute to youth marginalization, social deprivation, and experiences of distress through an exclusive reliance on individual interventions.

To conclude this section on the current context, it is worth noting that we are also living in a time when the identification and management of risk has become a central preoccupation. As Douglas (1992) observed, living in a risk society means we are "ready to treat every death as chargeable to someone's account, every accident as caused by someone's criminal negligence, every sickness a threatened prosecution” (p. 16). The proliferation of risk assessment tools and other professional technologies designed to quantify and eventually ameliorate "risk" in the lives of children, youth and families, is but one manifestation of this. In a risk culture, "it is the perception of threatening risks that determines thought and action” (Beck, 2000, p. 213), which can often generate a fearful stance towards the future (Diprose, 2008).

As just one example, we might consider the "Mimo baby monitor" which, according to the company website, offers peace of mind to parents and caregivers in the following ways:

- our new respiration sensors are non-contact, soft and comfortable for baby while also letting you check your baby's breathing, giving you the peace of mind that all is $\mathrm{OK}$

- with our temperature sensors you can know for sure that your little one is the perfect temperature with just a peek at your app

- with our clinically validates sleep algorithms, you can even track their sleep patterns over time 
International Journal of Child, Youth and Family Studies (2015) 6(4): 498-515

It is interesting to contemplate how our own CYC practices exploit, resist, manufacture, or exacerbate this culture of risk and fear. For example, how do we conceptualize risk and how do our professional interventions position us and those we work with? An even more difficult question is posed by Saraceno (2012) when she asks, "What are the implications for ethical engagement with our clients and with our communities when our livelihood is dependent on the suffering and disenfranchisement of others?” (p. 258). In other words, our conceptualization of risk needs to move beyond procedural talk of "assessment" and "management" towards a more critically reflexive posture that invites us to consider how our positioning as professionals and our use of specialized interventions may actually produce and/or perpetuate the very risks we are attempting to ameliorate.

These are complicated and troublesome questions that require richer, more politicized conceptualizations of practice that go beyond the articulation of professional ethics and competencies (Little, 2011; Loiselle et al., 2012; White, 2007). In other words, we need practice and pedagogical frameworks that can help us to engage with unprecedented levels of complexity.

\section{A World of Supercomplexity}

Living in the midst of multiple and competing knowledge claims, unparalleled levels of social change, and facing high levels of uncertainty, Ronald Barnett (2000, 2012) characterizes the times we are living in as more than simply complex. He suggests we are living in a time of supercomplexity. In a world of supercomplexity, everything is contested, risks are difficult to quantify, and we are required to engage with multiple open-ended questions, ambiguity, and competing frameworks. The problems and challenges we confront are often unrecognizable to us and we do not even have language or concepts to name what is going on. As Barnett (2000) puts it:

Supercomplexity denotes a fragile world but it is a fragility brought on not merely by social and technological change; it is a fragility in the way that we understand the world, in the way in which we understand ourselves and in the ways in which we feel secure about acting in the world. (p. 257)

In the field of CYC, multiple and conflicting ideas about children, youth, knowledge, research, practice, ethics, and professional identity abound, and no singular or straightforward answers are available to guide or guarantee "right action". This can contribute to an overall feeling of instability and vulnerability. Paradoxically, the ability to act in a world that is radically unknowable is perhaps the hallmark of professional preparedness in a world of supercomplexity (Barnett, 2012). According to Barnett, the task is not one of dissolving anxiety for this is recognized as impossible, but rather it is about developing a capacity to live with the anxiety, and even flourish under such conditions. In short, it requires "a willingness to live in contention" (Snelgrove et al., 2014, p. 3). As Barnett notes, this form of engagement with the world is fundamentally ontological in character (i.e., concerned with our ways of being), and has implications for how we might consider educating future practitioners: 
International Journal of Child, Youth and Family Studies (2015) 6(4): 498-515

It is the task of enabling individuals to prosper amid supercomplexity, amid a situation in which there are no stable descriptions of the world, no concepts that can be seized upon with any assuredness, and no value systems that can claim one’s allegiance with any unrivalled authority. (p. 69)

With this notion of supercomplexity in mind, in the next section I hope to invite more interesting and generative ways of thinking by critically scrutinizing some of our professional assumptions and approaches. Through a series of carefully crafted questions I intend to show that descriptions are not final, meanings are not settled once and for all, and things can always be otherwise (Gergen, 2009). I am not asking these questions as a judging outsider, but rather as one who is firmly embedded in the field and implicated in these practices. This questioning approach to practice is in keeping with a critical ethics of practice (Jeffrey \& Nelson, 2011; Rossiter, 2005; Skott-Myhre \& Little, 2014; White, 2011), where the confusing, messy, and contradictory nature of “caring” practice requires ongoing interrogation, critical reflexivity, and a high tolerance for uncertainty and contradiction.

\section{Constructions of Children, Youth, and Families}

Who comes to mind when we think about the children who are in need of "professional care”? What are we doing when we say we are "working with" children? What is it like for children to be "worked with"? What is the primary motif of CYC practice - playing, rescuing, empowering, organizing, educating, liberating, treating, intervening, controlling, counselling, radicalizing, loving? Who are the youth who are the objects of care in child and youth care? How do terms like "troubled", "in need", "at risk", "vulnerable”, or "marginalized" position young people and practitioners? What do such descriptions do? Who are the families who come to our attention? Which families do not? When "daily events" become sites of ongoing CYC interventions, are families ever outside of our professional gaze?

Each of these questions points to the reality that we are always working in the midst of struggle and contestation, where the security and certainty of our professional knowledge is always at risk of coming undone. In other words, professional identities and practices are always problematic, always precarious. In support of this idea, Stronach, Corbin, McNamara, Stark, and Warne (2002) closely examined nurse and teacher identities and noted that uncertainty is the defining narrative where "each moment of practice articulates an accommodation between the actual and the ideal, the possible and the desirable” (p. 131) - which could also fairly describe CYC practice.

\section{Constructions of Problems}

Meanwhile, it is worth asking this: What counts as a CYC problem? In the absence of problems, can CYC exist? What do our CYC "solutions" reveal about how problems have been framed? As just one example, if we are putting our energy into teaching young people how to cope better, how to be better problem-solvers and self- 
International Journal of Child, Youth and Family Studies (2015) 6(4): 498-515

regulators, through skill development and other resilience enhancement interventions, what assumptions are we making about what the problem is and who is responsible? Where is the onus for change primarily located? What is concealed from view?

When we resist the temptation to take problems for granted, and instead interrogate how the problems have been constructed, more space is opened up for thinking creatively, ethically, and politically. As just one example, if we were to make more explicit connections between so-called private troubles (i.e., PTSD, ADHD, anxiety, disordered eating, self-harm) and the larger sociopolitical and economic context, might traditional CYC problems perhaps rightfully become matters of public consideration and social responsibility (Fusco \& Baizerman, 2013; Rossiter, 2005)? While CYC has a long history of working in a "strengths-based way" it may be time to follow the lead of many of our CYC colleagues (Loiselle et al., 2012; Saraceno, 2012; Skott-Myhre, 2006) and start claiming "sociopolitically-engaged” as a defining characteristic of our field as a way to signal that we recognize the limits of individualized, decontextualized, and apolitical interventions. We will also need to think very carefully about how to theorize diversity in ways that go beyond "celebrating multiculturalism” (Skott-Myhre \& Little, 2014).

\section{Thinking About Differences}

There are multiple ways for thinking about differences within CYC. These include: differences in terms of power and privilege; world views, traditions, and conceptualizations of reality; theoretical and methodological orientations; sites of practice; as well as ethno-cultural identities, gender, ability, sexual orientation, and class backgrounds. Recently there has been increased attention paid to issues of cultural safety, cultural responsiveness, and cultural attunement across many helping fields, including CYC. At the same time, notions of diversity are highly contested and the dominant discourse of multiculturalism has been productively critiqued by many CYC scholars. ${ }^{1}$ For example, within liberal multiculturalism, there is typically an absence of any analysis of the workings of power and the primary imperative is to "embrace differences" or “celebrate diversity”. Ahmed (2012) talks about the ways that the word diversity can sometimes serve as a happy substitute for not talking about racism.

How do we think about diversity within CYC? Who comes to mind as the face of diversity? Do we take sufficient account of history and politics? What counts as a worthwhile, livable life? Whose vision of a preferred future is privileged in our work? What unspoken norms about "healthy childhood" are exerting their influence over our work? Whose cultural traditions are privileged when conceptualizing well-being, distress, and healing (Wexler \& Gone, 2012)? These are important questions to ask because, among other things, they remind us that while many of our professional goals and aspirations remain unspoken, they still actively shape how we think about ourselves and those we care for. Further, professionalism is itself a culture that takes certain

${ }^{1}$ See Skott-Myhre and Little (2014) for an excellent volume on the limitations of the discourse of multiculturalism within a contemporary Canadian context. 
International Journal of Child, Youth and Family Studies (2015) 6(4): 498-515

understandings for granted, including the value of expertise and professional knowledge.

\section{Professional Identities}

We have a long tradition in our CYC field of debating the respective benefits and limitations of professionalization. Recently there was yet another lively and spirited discussion about professionalization in a special issue of Child \& Youth Services. In it, Fusco and Baizerman (2013) concluded that,

Ours is a turbulent world - in thought, politics, and economics, socially and culturally. There is a reformation occurring across disciplines, a challenge to heretofore dominant scientific, moral, social, and political paradigms of what is right, good, and effective. (p. 96)

This emphasis on constant change and the need for an ongoing reflexive posture towards our knowledge and practice frameworks is consistent with the position I am setting out here. It also holds strong resonance with the recent work of Scott (2012) who cautioned against seeking singularity or "purity” in CYC, and Little (2011) who used her own experiences as a CYC-educated scholar and practitioner to challenge the idea that there exists a "real CYC" that can be distinguished from related, but counterfeit versions.

It seems that it is difficult for many of us to think about "professionalism" outside a very traditional and normative framework (i.e., specialized body of knowledge, code of ethics, authority to make decisions). In addition to the thoughtful and generative questions about professionalization that Fusco and Baizerman (2013) raise in their article, such as "why that?" and "to what end, for young people and community?" (p. 97), I would like to add two of my own. First, by becoming part of the dominant group of "recognized professionals" are we not simply perpetuating the existing social order; one which is governed by the creation of hierarchies; centres and margins; insiders and outsiders? Secondly, if we move in this direction, who then is setting the terms for how we think about ourselves and the children, youth, and families we support?

\section{CYC for the Unsettled Times}

Clearly we are living in unsettled times. Having just stepped into the role of Director of the School of Child and Youth Care at the University of Victoria, I understand the importance of bringing an enlarged perspective to the field, one which recognizes the valuable work that we all do to support children, youth, and families. Thanks to the tireless contributions of so many CYC colleagues, we have witnessed the emergence of a unique, visible, and skilled workforce that is highly regarded for its unique contributions to promoting child and youth well-being in group care, residential treatment programs, and other school and community settings. At the same time, the field of CYC is also unfolding in many new directions at once.

For example, graduates from our undergraduate program are qualified to work in child protection if they take the child protection specialization. We also have a child life specialization for those who want to care for critically ill children in hospital settings. We 
International Journal of Child, Youth and Family Studies (2015) 6(4): 498-515

have an Indigenous specialization for those who want to practice in culturally informed and respectful ways with First Nations, Inuit, and Métis communities. We have an early years stream that enables students to receive certification in early childhood education so that they can practice in a variety of early years contexts. Several former students who have graduated from our M.A. and Ph.D. program are now working as faculty members in post-secondary contexts, educating the next generation of CYC practitioners and scholars. Many others are working as research analysts, policy consultants, child and youth mental health clinicians, private practitioners, and leaders in a variety of national and international contexts. In addition to their educational qualifications in CYC, many of our alumni are seeking additional forms of certification through a range of professional bodies (e.g., Child Life, Early Childhood, Clinical Counsellors, among others). Their business cards grant them many different titles; however, their practices are always contextually sensitive, holistic, strengths-based, collaborative in spirit, and grounded in a very strong set of ethical and political commitments (White, 2011).

Opening up the field in so many new directions is a source of worry and consternation for some, and a source of excitement and exhilaration for others. We are constantly living the tension of honouring our foundations on the one hand and pushing the field in new directions and opening up new horizons on the other. No matter where you sit on the issue, the reality is that CYC is already hybrid! And as I hope to show next, this ethos of hybridity, multiplicity, agility, and fluidity is one that I think very much suits the times we are living in.

\section{Living the Tensions and Adding to the Complexity}

If the aim is to "be willing to live in contention" (Snelgrove et al., 2014), how might we prepare ourselves, as well as future CYC practitioners and scholars, to thrive in the midst of unprecedented levels of complexity? To begin, we can add to the complexity by extending our thinking and reworking existing theories (Barnett, 2012). Part of this effort will entail generating new questions, visions, and vocabularies for rethinking a changing world. For example, this could include advancing new ways of theorizing the self; enlarging our ethical vision; and complicating and politicizing our current notions of practice and research in CYC (Kouri, 2014; Kouri \& White, 2014; Pacini-Ketchabaw \& Pence, 2011; Skott-Myhre \& Little, 2014; White, 2007). This work will inevitably involve disruption, change, and new ways of doing things. This will also mean moving in multiple directions at once and maintaining a diversity of descriptive forms in both our theorizing and in our practices (Stronach et al., 2002).

Meanwhile, by paying close attention to the effects of our preferred practices in CYC, some new and creative spaces can be opened up. For example, taking inspiration from the work of Sarah Ahmed (2012), who "followed diversity around" in higher education contexts, if we follow CYC around and ask what it is doing, what might we discover? Here are just a few possibilities:

- CYC comes into being by saying "who we work with"

- CYC explains itself by saying "where CYC practitioners can be found" 
International Journal of Child, Youth and Family Studies (2015) 6(4): 498-515

- To do CYC is to reflect on a "capital-S" Self

- CYC talks in (concentric) circles

- $\quad$ CYC is about setting clear boundaries

- To do CYC is to be worried

- CYC is not to be found "in offices"

Among other things, it is worth noting that all of our current understandings about CYC practice are historically and culturally specific. With this in mind, we might ask: What were the conditions and contexts that set the stage for CYC's arrival? What is the history of some of our most cherished CYC ideas and preferred practices (e.g., use of Self; life space interventions)? What did these preferred practices emerge in response to? How did these particular ways of seeing and doing things gain such traction in our field? At the time of their emergence, what were these ideas taking a stand against? What are the effects of these ways of thinking and working on the children, youth, and families who seek our help today? What identities do they make available for practitioners? Each of these questions reminds us that we are always entangled with, and responding to, that which has come before. We need to continuously ask how our earlier conceptualizations of CYC practice and understandings of children, youth, and families fit the current times.

Our work is always historically situated, relationally negotiated, and ethically saturated. This way of thinking contrasts with many traditional views of professional ethics which regard ethics as an "add-on" to practice and typically locate responsibility for "doing ethics" with the individual practitioner. The view being advanced here is that all CYC practices are ethical encounters and ethics is always a collective venture that is developed through conversation, joint story telling, community, and relational practices (Chapman et al., 2013; White, 2011). We have a long tradition within CYC that draws on artistic and fluid metaphors for conceptualizing the work. Descriptions of CYC practice often foreground the language of conversations, dialogue, mutual inquiry, wisdom, and narratives of care. We also need to attend to the sociopolitical context of problems because our practices are never neutral or ahistorical (Jeffery \& Nelson, 2012). Even "relational meaning-making" takes place within a sociopolitical context where certain dominant explanatory frameworks strongly influence what can be thought, said, and imagined.

\section{Unfolding Into the Unknown Future}

As I have tried to show here, the field of CYC is already poly-vocal. We do not have to settle for either/or choices but can continue to explore "third spaces" that creatively engage with neither/both/and (Little, 2011; Tuck, 2009). I have further suggested that we might want to reimagine professionalism for the times. Maybe we are already leading the way in terms of showcasing an unbounded, agile, hybrid, relevant, remixed, boundary-crossing form of professionalism (CYC as "mash-up"). What new stories can we co-create together? Are there any stories we might need to retire? What stories might we tell that would enable us to build a professional identity based on multiple narratives and our earned reputation (Stodd, 2014)? 
International Journal of Child, Youth and Family Studies (2015) 6(4): 498-515

The task ahead is one of not just coping with uncertainty and contingency, but thriving, prospering, and adding to the complexity (Barnett, 2012). We will maintain our spirit of aliveness and be most awakened to our collective potential by sustaining our creative differences, thriving in the midst of complexity, and by dwelling responsibly. Just because the world we are living in is constantly changing and always uncertain does not mean we must throw up our hands in despair and concede defeat. On the contrary, such a world demands a new form of agility, responsiveness, and accountability. As I have argued here, we need an ethos for the times that is grounded in the knowledge of particular places and histories, governed by an awareness of global realities and settlercolonial relations, and which pursues an ongoing commitment to justice (deFinney et al., 2012; Newbury, 2009; Snelgrove et al., 2014). Recognizing our interconnectedness and making a point of dwelling responsibly are in keeping with Indigenous world views as well as early understandings of the word ethos.

[T] he ethos of dwelling is a space of hospitality and respect for the more-thanhuman world.... To dwell responsibly is thus to make room for others by dwelling within certain limits, recognizing that we become who we are as human beings only in response to a complex world which exceeds human existence and comprehension. (Guenther, 2002, p. 38)

In sum, when we think about CYC practice as a series of dilemmas and openended questions, as opposed to a set of predetermined answers that can be mapped onto a stable and knowable world, perhaps we can come to our work with greater humility and a more useful set of expectations. At the very least, such an ethos involves supporting ourselves and others to live lives of dignity and purpose, experience love and belonging, pursue culturally meaningful goals, and live in a just world. 
International Journal of Child, Youth and Family Studies (2015) 6(4): 498-515

\section{References}

Ahmed, S. (2004). The cultural politics of emotion. New York: Routledge. http://dx.doi.org/10.4324/9780203700372

Ahmed, S. (2012). On being included: Racism and diversity in institutional life. London: Duke University Press. http://dx.doi.org/10.1215/9780822395324

Aldarondo, E. (Ed.). (2007). Advancing social justice through clinical practice. Mahwah, NJ: Lawrence Erlbaum Associates. http://dx.doi.org/10.4324/9780203936689

Barnett, R. (2000). Supercomplexity and the curriculum. Studies in Higher Education, 25(3), 255-265. http://dx.doi.org/10.1080/713696156

Barnett, R. (2012). Learning for an unknown future. Higher Education Research \& Development, 31(1), 65-77. http://dx.doi.org/10.1080/07294360.2012.642841

Beck, U. (2000). Risk society revisited: Theory, politics and research programmes. In B. Adam, U. Beck, \& J. van Loon (Eds.), Risk society and beyond: Critical issues for social theory (pp. 210-229). London: Sage. http://dx.doi.org/10.4135/9781446219539.n12

Braidotti, R. (2010). On putting the active back into activism. New Formations, 68(16), 42-57. http://dx.doi.org/10.3898/newf.68.03.2009

Chapman, C., Hoque, N., \& Utting, L. (2013). Teaching a personal-is-political ethics: Reflexive conversations in social work. Intersectionalities: A Global Journal of Social Work Analysis, Research, Polity, and Practice, 2, 24-50.

Deepak, A. (2012). Globalization, power and resistance: Postcolonial and transnational feminist perspectives for social work practice. International Social Work, 55(6), 779-793. http://dx.doi.org/10.1177/0020872811414038

deFinney, S., Little, J. N., Skott-Myhre, H., \& Gharabaghi, K. (2012). Roundtable: Conversations on conversing in child and youth care. International Journal of Child, Youth \& Family Studies, 3(2/3), 128-145.

diTomasso, L. (2012). More equal than others: The discursive construction of migrant children and families in Canada. International Journal of Child, Youth and Family Studies, 3(2/3), 331-348.

Diprose, R. (2008). Biopolitical technologies of prevention. Health Sociology Review, 17(2), 141-150. http://dx.doi.org/10.5172/hesr.451.17.2.141

Douglas, M. (1992). Risk and blame: Essays in cultural theory. London: Routledge. http://dx.doi.org/10.4324/9780203430866

Farmer, P. (2003). Pathologies of power: Health, human rights and the new war on the poor. Oakland, CA: University of California Press. 
International Journal of Child, Youth and Family Studies (2015) 6(4): 498-515

Fellows, M. L., \& Razack, S. (1998). The race to innocence: Confronting hierarchical relations among women. Journal of Gender, Race and Justice, 1, 335-352.

Fondacaro, M., \& Weinberg, D. (2002). Concepts of social justice in community psychology. American Journal of Community Psychology, 30(4), 473-492. http://dx.doi.org/10.1023/a:1015803817117

Fuller, S. (2014). A modest proposal for all future keynotes. The Sociological Imagination. Retrieved from http://sociologicalimagination.org/archives/15219

Fusco, D., \& Baizerman, M. (2013). Professionalization in youth work? Opening and deepening circles of inquiry. Child \& Youth Services, 34(2), 89-99. http://dx.doi.org/10.1080/0145935x.2013.785874

Gergen, K. (2009). Relational being: Beyond self and community. New York: Oxford University Press. http://dx.doi.org/10.1093/acprof:osobl/9780199846269.001.0001

Giroux, H. (2014). Neoliberalism's war on higher education. Chicago, IL: Haymarket Books.

Guenther, L. (2002). Towards a phenomenology of dwelling. Canadian Journal of Environmental Education, 7(2), 38-46.

Harvey, J. (2007). Whiteness and morality: Pursuing racial justice through reparations and sovereignty. New York: Palgrave. http://dx.doi.org/10.1057/9780230604940

Held, D., McGrew, A., Goldblatt, D., \& Perraton, J. (1999), Global transformations: Politics, economics and culture. Stanford, CA: Stanford University Press.

Hoskins, M. (2012). Stories of another kind: Engaging in generative conversations in pedagogical spaces. Child \& Youth Services, 33(3/4), 237-257. http://dx.doi.org/10.1080/0145935x.2012.745789

Jeffery, D., \& Nelson, J. (2011). 'What are we to do about difference?' Race, culture and the ethical encounter. Ethics and Social Welfare, 5(3), 247-265. http://dx.doi.org/10.1080/17496535.2011.559359

Kouri, S. (2014). Child and youth care to come. In H. Skott-Myhre \& J. N. Little (Eds.), Troubling multiculturalism (pp. 32-62). London: Routledge.

Kouri, S., \& White, J. (2014). Thinking the other side of youth suicide: Engagements with life. International Journal of Child, Youth \& Family Studies, 5(1), 180-203.

Law, J., \& Urry, J. (2004). Enacting the social. Economy and Society, 33(3), 390-410.

Lee, J., \& de Finney, S. (2008). Using popular theatre for engaging racialized minority girls in exploring questions of identity and belonging. Child \& Youth Services, 26(2), 95-118. http://dx.doi.org/10.1300/j024v26n02_06 
International Journal of Child, Youth and Family Studies (2015) 6(4): 498-515

Little, J. N. (2011). Articulating a child and youth care philosophy: Beyond binary constructs. In A. Pence \& J. White (Eds.), Child and youth care: Critical perspectives on pedagogy, practice and policy (pp. 3-18). Vancouver: UBC Press.

Little, J. N., \& Walker, M. (2014). Reconceptualizing multicultural discourse as shifting geographies. In H. Skott-Myhre \& J. N. Little (Eds), Troubling multiculturalism (pp. 143-154). London: Routledge.

Loiselle, E., de Finney, S., Khanna, N., \& Corcoran, R. (2012). "We need to talk about it!” Doing CYC as politicized praxis. Child \& Youth Services, 33(3), 178-205. http://dx.doi.org/10.1080/0145935x.2012.745778

Middleman, R., \& Wood, G. (1990). Skills for direct practice social work. New York: Columbia University Press.

Newbury, J. (2009). Contextualizing child and youth care: Striving for socially just practice. Relational Child and Youth Care, 22(4), 20-29.

Pacini-Ketchabaw, V., \& Pence, A. (2011). The postmodern curriculum: Making space for historically and politically situated understandings. Early Childhood Australia, 36(1), [NOTE: any page numbers?]

Pacini-Ketchabaw, V. (2014). Postcolonial entanglements: Unruling stories. In H. SkottMyhre \& J. N. Little (Eds.), Troubling multiculturalism (pp. 129-142). London: Routledge.

Patil, V. (2013). From patriarchy to intersectionality: A transnational feminist assessment of how far we've really come. Signs: Journal of Women in Culture \& Society, 38(4), 847-867. http://dx.doi.org/10.1086/669560

Prilleltensky, I., Rossiter, A., \& Walsh-Bowers, R. (1996). Preventing harm and promoting ethical discourse in the helping professions: Conceptual, research, analytical, and action frameworks. Ethics \& Behavior, 6(4), 287-306. http://dx.doi.org/10.1207/s15327019eb0604_1

Raphael, D. (2014). Social determinants of children's health in Canada: Analysis and implications. International Journal of Child, Youth \& Family Studies, 5(2), 220 239.

Roman, L. G. (2003). Education and the contested meanings of 'global citizenship.' Journal of Educational Change, 4(3), 269-293. http://dx.doi.org/10.1023/b:jedu.0000006164.09544.ac

Rossiter, A. (2005). Discourse analysis in critical social work: From apology to question. Critical Social Work, 6(1). Retrieved from http://www1.uwindsor.ca/criticalsocialwork/discourse-analysis-in-critical-socialwork-from-apology-to-question 
International Journal of Child, Youth and Family Studies (2015) 6(4): 498-515

Saraceno, J. (2012). Mapping whiteness and coloniality in the human service field: Possibilities for a praxis of social justice in child and youth care. International Journal of Child, Youth \& Family Studies, 3(2/3), 248-271.

Scott, D. (2012). Escaping purity: Lessons for child and youth care. International Journal of Child, Youth \& Family Studies, 3(2/3), 187-197.

Skott-Myre, H. (2006). Radical youth work: Becoming visible. Child \& Youth Care Forum, 35(3), 219-229. http://dx.doi.org/10.1007/s10566-006-9010-2

Skott-Myhre, H. A., \& Little, J. N. (Eds). (2014). Troubling multiculturalism. New York: Routledge.

Snelgrove, C., Dhamoon, R., \& Corntassel, J. (2014). Unsetlling settler colonialism: The discourse and politics of settlers, and solidarity with Indigenous nations. Decolonization: Indigeneity, Education \& Society, 3(2), 1-32.

Stodd, J. (2014). Julian Stodd's learning blog. Retrieved on July 29, 2014 from: http://julianstodd.wordpress.com/about/

Stronach, I., Corbin, B., McNamara, O., Stark, S., \& Warne, T. (2002). Towards an uncertain politics of professionalism. Journal of Education Policy 17(1), 109138. http://dx.doi.org/10.1080/02680930110100081

Tuck, E. (2009). Suspending damage: A letter to communities. Harvard Educational Review, 79(3), 409-427. http://dx.doi.org/10.17763/haer.79.3.n0016675661t3n15

Wexler, L. M., \& Gone, J. P. (2012). Culturally responsive suicide prevention in Indigenous communities: Unexamined assumptions and new possibilities. American Journal of Public Health, 102(5), 800-806. http://dx.doi.org/10.2105/ajph.2011.300432

White, J. (2007). Knowing, doing and being in context: A praxis-oriented approach to child and youth care. Child and Youth Care Forum, 36(5), 225-244. http://dx.doi.org/10.1007/s10566-007-9043-1

White, J. (2011). Re-stor(y)ing professional ethics in child and youth care: Towards more contextualized, reflexive and generative practices. In A. Pence \& J. White (Eds.), Child and youth care: Critical perspectives on pedagogy, practice and policy (pp. 33-51). Vancouver, BC: UBC Press.

White, J. (2012). Youth suicide as a ‘wild problem’: Implications for prevention practice. Suicidology Online, 3, 42-50. 